\section{Ophthalmologists with conjunctivitis: are they fit to work?}

S.K. WEBBER, D.G.S. BLAIR, A.R. ELKINGTON, C.R. CANNING
S.K. Webber

D.G.S. Blair

A.R. Elkington

C.R. Canning

Southampton Eye Unit Southampton General Hospital

Southampton, UK

Mr C.R. Canning

Southampton Eye Unit Southampton General

Hospital

Tremona Road

Southampton SO16 6YD, UK

Tel: $+44(0) 1703777222$

Fax: $+44(0) 1703794120$

Received: 1 December 1998 Accepted in revised form: 24 June 1999

\begin{abstract}
Purpose To establish current opinion as to whether ophthalmologists with conjunctivitis are fit to work.

Methods One hundred and sixty

ophthalmology units in the United Kingdom were sent a postal survey enquiring about work practices when an ophthalmologist contracts conjunctivitis.

Results One hundred and five replies were received. Twenty-nine per cent of respondents said the ophthalmologist should stay off work while $7 \%$ said he or she should continue as usual. There was no concordance as to whether viral or bacterial conjunctivitis posed a greater problem. There is evidence that ophthalmologists have been implicated in the spread of epidemics of viral conjunctivitis but also reports of ophthalmologists who have continued to work with no reported spread of infection.

Conclusion In view of the lack of consensus the authors are unable to recommend evidencebased clinical guidelines, but would suggest that use of modem diagnostic laboratory techniques may help in making the decision as to whether to continue at work or not.
\end{abstract}

Key words Conjunctivitis, Epidemic keratoconjunctivitis, Hospital infection, Iatrogenic illness

Conjunctivitis is often viewed by ophthalmologists as a trivial condition. However, for some patients it is extremely uncomfortable and it can cause significant visual morbidity; it is also often highly contagious. When ophthalmologists have conjunctivitis they face a dilemma: Should they stay off work so minimising the risk of spreading the infection to their colleagues and patients? This may cause difficulties within the department, including the need to reschedule appointments and operations, or to find another ophthalmologist to take on the work.

Alternatively, the ophthalmologist could continue to work but risk spreading the infection to other people who, in turn, will suffer discomfort, pain and perhaps reduced vision. Often ophthalmologists feel they should absent themselves from work but feel guilty about the extra workload shifted onto their colleagues. Ophthalmologists may feel they should not be at home unless they are unwell.

In such cases as these, where there is a conflict of interest, the route taken is often as a result of conscience rather than good medical practice. In these circumstances departmental guidelines could help decision-making and may lead to reduced 'moral anxiety' in sufferers.

The aim of this paper is to survey current practice in Ophthalmic Units within the United Kingdom and to discuss the results in the light of a literature review.

\section{Method}

One hundred and sixty ophthalmic units were surveyed. A two-page, simple questionnaire was despatched to one named consultant in each unit together with a letter of explanation and a stamped addressed envelope. The estimated time required to complete the questionnaire was 5 minutes. The consultant was asked to answer the questionnaire according to unit policy; where there was none then the respondent should answer from personal practice. The responses were collated on a spreadsheet (Microsoft Excel 5.0).

\section{Results}

One hundred and five responses were received $(66 \%)$. One questionnaire was returned as the addressee had left the department. Not all respondents answered all the questions.

Respondents were asked whether there was a departmental policy on whether they should continue to work with conjunctivitis. Of those who answered the question, over $90 \%$ said that there was no departmental policy, either official or unofficial. Of the 10 units reported to have a policy, 4 were said to be official and 6 unofficial (Fig. 1). Eighty-eight per cent of respondents' answers were based on personal practice.

When asked what action, if any, should be taken when an ophthalmologist has conjunctivitis, $7 \%$ said the ophthalmologist could continue working as usual, $19 \%$ that the ophthalmologist could perform clinics but no surgery, $26 \%$ that they should perform nonclinical duties only and $29 \%$ said the ophthalmologist should stay off work. In 


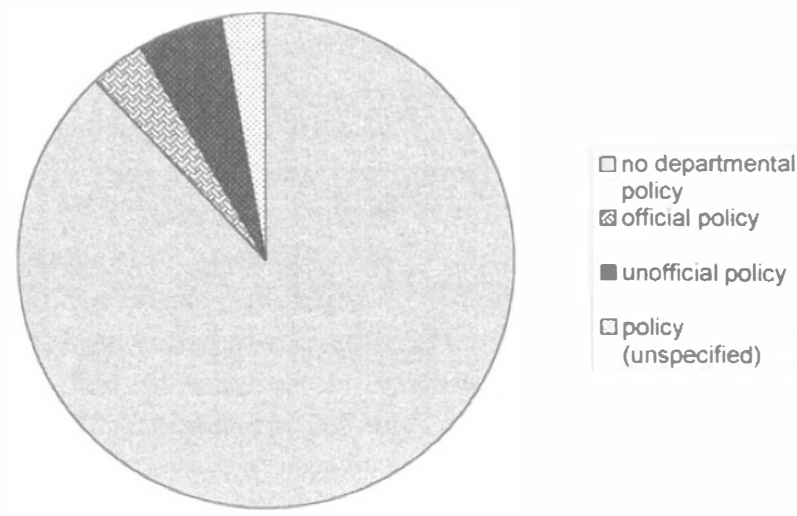

Fig. 1. Number of departmental policies.

addition, $16 \%$ of respondents gave a combination of answers dependent on the aetiology and severity of infection.

Three-quarters said that it would make no difference to their policy if they knew whether the infection was bacterial or viral. On the other hand the remaining quarter said that the aetiology would influence their policy. There was no concordance as to whether viral or bacterial conjunctivitis was viewed as a greater risk: comments ranged from 'Non-clinical duties only if adenovirus' to 'Viral, carry on as usual; if bacterial, no operating' and 'Stay at home if adenovirus'. Twelve respondents expressed a clear opinion as to whether bacterial or viral conjunctivitis required greater restriction of working activity. Seven stated that viral conjunctivitis required more work restriction than bacterial and five to the contrary.

Half the respondents said their staff were swabbed for microbiological investigation. The reasons given for swabbing were: to identify the type of organism and allow appropriate treatment (24), epidemiology (10), for use if the condition fails to settle (3), to assess the likely duration of infection (3), medico-legal reasons (1), good medical practice (2) and Chlamydia (1).

If practice is to be restricted, how long should this stay in force? Until asymptomatic was the answer from $64 \%$ of those answering this question, $13 \%$ gave a specific period of time and $21 \%$ gave comments including 'Until non-infective' (4), 'Until culture negative' (3) or 'Until clinically improved' (11).

The reasons given for restricting practice were: to prevent spread of infection to patients $(30 \%)$ or to both colleagues and patients (70\%).

When asked whether the respondent had any personal knowledge of an infection having been spread from an ophthalmologist, $28 \%$ answered yes and $72 \%$ said they had none. Of those answering in the positive, this was supported by anecdotal evidence in 26 of the 29 responses and by peer reviewed and published evidence in 4 . An aetiological agent was named by 11 respondents and in all cases it was adenovirus. Two respondents identified specific doctors and one a patient as the sources of infection in an epidemic. One case had a laser lens cited as a fomite. Six respondents $(9 \%)$ reported occasions when a person suffered a serious complication of infection and in all cases this was a viral keratitis, sometimes severe enough to reduce visual acuity.

On the contrary, $38 \%$ of respondents $(n=38)$ were aware of occasions when an ophthalmologist continued to work and no subsequent spread was identified. Seven respondents considered the infection to be viral and one, bacterial. Some respondents stated that precautions were taken to avoid spread, but they did not elaborate on the specific precautions used.

\section{Discussion}

The most notable finding from this survey was that there was no consensus as to whether adenoviral or bacterial conjunctivitis required more restriction to usual working practice. The reason for restricting practice was to prevent spread to patients and colleagues. Therefore, it can be inferred that there is no consensus as to whether virus or bacteria confers the greater risk of infection.

Twenty-eight per cent of respondents said that they knew of occasions when a doctor had spread conjunctivitis to others, yet $38 \%$ said that they knew of occasions when doctors had continued working and the infection was not known to have spread. It is suspected that there has been duplicate reporting of cases of known spread. Adenovirus was cited as the infective agent in 11 cases of known spread and in 7 of no reported spread. This would suggest that, although possible, spread is by no means inevitable in cases of viral conjunctivitis.

Reference to Fig. 2 would suggest that clinicians with personal experience of spread of conjunctivitis are more likely to recommend avoiding clinical duties than those without this experience.

Some published reports suggest that the outbreaks were terminated or limited, at least in part, by increased awareness of infectivity and a commensurate increase in hygiene, such as hand-washing, tonometer cleaning and slit-lamp cleansing. ${ }^{1-4}$ Doctors were implicated in the spread of infection in some outbreaks, ${ }^{5}$ but it is not clear from the report whether they were acting as vectors or hosts for the virus. Therefore it is unknown whether stringent hand-washing precautions and other cleansing procedures would allow an infected doctor to continue to practise with little risk to his or her patients. It has been shown in one study that the hands of $46 \%$ of patients with epidemic keratoconjunctivitis were culture positive for adenovirus. ${ }^{6}$ Indeed, it has been demonstrated that

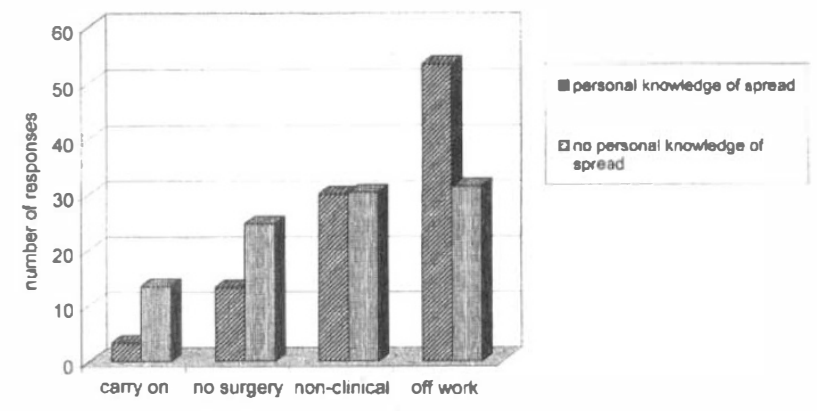

Fig. 2. Relationship between action recommended and previous personal knowledge of spread of infection. 
hand-washing markedly reduces the virus load on the hand. ${ }^{7}$ Although it is unknown whether the serotypes in these cases of 'no spread' are different from those implicated in epidemics, the fact that so many doctors have continued to practise with no reported adverse effect to others would suggest that, with precautions, in some cases it is safe to continue working. Most junior doctors working in an eye casualty department will see patients with infective conjunctivitis daily. These doctors will usually wash their hands after seeing such a patient. Relatively few doctors catch conjunctivitis from their patients. Thus, it would seem that awareness of the possibility of infection and hand-washing prevents actual spread in most cases.

Adenoviral conjunctivitis is said to have an incubation period averaging 14 days (range $3-24$ days $^{2,4,8-10}$ ) with an infective period of 14 days $^{2}$ from the commencement of the conjunctivitis. The virus itself is most commonly isolated in the first 10-14 days after the onset of infection but the precise period of contagiousness has not been defined. The duration of the attack has been linked to the serotype of virus isolated. ${ }^{8}$ Symptoms of conjunctivitis may persist for 1-4 weeks. ${ }^{9}$ With the different causal serotypes it is difficult to give a precise contagious period. The morbidity associated with

keratoconjunctivitis can be significant; sub-epithelial keratopathy can last for several months or even years. ${ }^{8}$

Half the respondents said that staff were swabbed for microbiological investigation and the most common reason given was to identify the causative microorganism and so estimate the time to be spent off work. Personal communication with the local virology laboratory reveals that the average time to obtain viral identification information is 10-14 days. The method used is that of virus culture. It is clear that confirmation from microbiological tests will only be obtained at about the same time that the condition is usually resolving. Therefore, one has to question the validity of performing such investigations for anything other than research reasons. Diagnosis of the type of conjunctivitis is usually made on clinical grounds although this can be difficult; in one study only $16 \%$ of cases were correctly diagnosed. ${ }^{8}$ However, within the last decade other methods of virus identification have been developed. Immunoassay can yield a result in $1 \mathrm{day}^{5}$ and polymerase chain reaction (PCR) may yield a result within hours. ${ }^{11}$ Clearly, these tests could be useful in deciding the appropriate action in the case of an ophthalmologist with conjunctivitis. But, as yet, they are available in only a limited number of centres.

When a specific time to restrict practice was mooted the answers varied depending upon whether the infection was considered to be viral or bacterial. Those who considered the infection to be bacterial recommended in the order of 1-3 days, those favouring viral infection recommended between 1 and 3 weeks; this seems to reflect accurately the known infective period.

In deciding whether to cease work when infected one has to consider the potential legal ramifications of the infection of a patient. Personal communication with the
Medical Defence Union revealed that there has not been a case brought to their attention of a patient alleging infection by their doctor. However, they do refer to the 'Duties of a Doctor' as published by the General Medical Council: 'If you have or are carrying a serious communicable condition ... you must take, and follow, advice from a consultant in Occupational Health or another suitably qualified colleague on whether, and in what ways, you should modify your practice. Do not rely on your own assessment of the risk to patients. ${ }^{12}$ This survey highlights the fact that no coherent assessment of risk exists, hence any advice sought will generally be based on previous personal experience and not evidencebased guidelines. This, surely, is poor clinical practice.

At the onset of this survey the authors were hoping to produce guidelines for ophthalmologists suffering with conjunctivitis. It is known that adenovirus infection is highly contagious, but that strict hygiene measures can limit the spread of the disease. We would suggest that in clear cases of viral infection the doctor should stay off work, where staffing levels permit this. However, where absence from work would cause a serious effect to the local population he or she may be permitted to work with assiduous hygiene measures. In cases where the infecting agent is debatable on clinical grounds a sample sent to a regional laboratory for immunoassay or PCR may allow the doctor to return to work if negative for virus.

\section{References}

1. Buehler JW, Finton RJ, Goodman RA, Choi K, Hierholzer JC, Sikes RK, Elsea WR. Epidemic keratoconjunctivitis: report of an outbreak in an ophthalmology practice and recommendations for prevention. Infection Control 1984;5:390-4.

2. Barnard DL, Dean Hart JC, Marmion VJ, Clarke SKR. Outbreak in Bristol of conjunctivitis caused by adenovirus type 8, and its epidemiology and control. BMJ 1973;2:165-9.

3. Tullo AB, Higgins PG. An outbreak of adenovirus keratoconjunctivitis in Bristol. Br J Ophthalmol 1979;63:621-6.

4. Lipton J, Patterson A. Epidemic keratoconjunctivitis in Liverpool. J R Coll Gen Practitioners 1984;34:519-20.

5. Ankers HE, Klapper PE, Cleator GM, Bailey AS, Tullo AB. The role of a rapid diagnostic test (adenovirus immune dotblot) in the control of an outbreak of adenovirus type 8 keratoconjunctivitis. Eye 1993;7(Suppl): 15-7.

6. Azar MJ, Dhaliwal DK, Bower KS, Kowalski RP, Gordon YJ. Possible consequences of shaking hands with your patients with epidemic keratoconjunctivitis. Am J Ophthalmol 1996;121:711-2.

7. Clarke SKR, Dean Hart JC, Barnard DL. The disinfection of instruments and hands during outbreaks of epidemic keratoconjunctivitis. Trans Ophthalmol Soc UK 1972;92:613-7.

8. Darougar S, Monnickendam MA, Woodland RM.

Management and prevention of ocular viral and chlamydial infections. Crit Rev Microbiol 1989;16:369-407.

9. Baum SG. Adenoviridae. In: Mandell GL, Douglass RG, Bennett JE, editors. Principles and practice of infectious diseases. 4th ed. New York: Churchill Livingstone, 1995:1382-6.

10. Harding SP, Mutton, KJ, Hgam A, Wermenbol AG. An epidemic of keratoconjunctivitis due to adenovirus type 37 . Eye 1988;2:314-7.

11. Cooper RJ, Yeo AC, Bailey AS, Tullo AB. Adenovirus polymerase chain reaction assay for rapid diagnosis of conjunctivitis. Invest Ophthalmol Vis Sci 1999;40:90-5.

12. General Medical Council. Good medical practice, para 20, p 7. In: Duties of a doctor, 1995. 